\title{
Research productivity of the state universities of Sri Lanka, a case based on SciVal and the contribution of the libraries towards excellence
}

\author{
P. Wijetunge ${ }^{1}$, A. Silva ${ }^{2}$, P.K.S. Manatunga ${ }^{3}$
}

\begin{abstract}
This paper discusses the research productivity of five state universities of Sri Lanka during 2015-2018, using scholarly output, citation impact and collaboration metrics of SciVal, and the contribution of the university libraries towards research excellence. Five multi-disciplinary state universities; University of Colombo (UoC), Kelaniya (UoK), Peradeniya (UoP), Ruhuna (UoR) and Sri Jayewardenepura (UoSJP) were selected as the sample. During the study period, 4723 publications and 3831 authors have been recorded, of which UoC and UoP records the highest numbers. UoR records the highest publications in top journal percentile and highest number of views (72) among the five universities. A total of 33104 citations are reported while UoP depicts the highest citation count (18322) as an individual university, while UoR records the highest h5-index (39). Highest Field Weighted Citation Impact (3.18) and the highest citations per publication (12.4) is recorded by UoP while the highest output in top citation percentile $(32.5 \%)$ is recorded by UoR. UoR records the highest overall international collaboration (74.4) during the studied period and UoP records the highest academic/corporate collaboration (2.2). University libraries provide collections and conducive environments for researchers, training in searching for information, referencing styles and use of reference management software, plagiarism detection and they maintain Institutional Repositories. The study established that there is much scope for university libraries to expand the services to support research productivity and recommends that librarians should consider on more current support areas like research data management, measuring research impact, and digital curation in order to support their universities to achieve excellence in research productivity.
\end{abstract}

Keywords: Citation Impact, Collaboration, Scholarly output, Sri Lanka, State Universities, SciVAL, Research Productivity

\footnotetext{
${ }^{1}$ Librarian, University of Colombo, Sri Lanka, Email: librarian@.lib.cmb.ac.lk

(iD) https://orcid.org/0000-0003-4139-8900

${ }^{2 \& 3}$ Senior Assistant Librarian, University of Colombo, Sri Lanka.

Emails: anusilva@lib.cmb.ac.lk, kalpism@lib.cmb.ac.lk
} 


\section{Introduction}

Research performance of an academic institution has become a key impact factor in ranking, student recruitment and funding both within the academic community and beyond. Funding bodies have emphasized more on monitoring the potential and actual impact of the research projects they fund in order to assure that publicly funded research makes a substantial contribution to a nation's competitiveness, and thus to the welfare of its citizens (Ball \& Duke 2015). The literature indicates that two approaches have been used to measure the research productivity. Micro economic approach has been adopted by researchers like Abramo and D'Angelo (2014), Aponsu (2017) and Günay and Haliloğlu (2018). A bibliometric approach has been adopted by researchers like Bornmann and Leydesdorff (2013), Erfanmanesh, Tahira and Abrizah (2017) and Gadhoum and Karam (2016). In addition, Research intelligence tools such as SciVal enable the evaluation of research productivity using different research metrics.

SciVal (Elsevier 2019a), is a tool built on the Scopus database and provides broad range of metrics which enable the librarians to provide more informed support to develop research productivity of the universities. It offers quick, easy access to the research productivity of over 12,000 research institutions and 230 countries and regions (Elsevier 2019a). "SciVal allows visualization of research performance, benchmark relative to peers, develop strategic partnerships, identify and analyze new, emerging research trends, and create uniquely tailored reports (Elsevier 2019b). It offers 27 different metrics which can be grouped in different combinations to provide seven major categories based on the insights provided; Awards granted, Collaboration, Published, Viewed, Cited, Economic impact and societal impact (Elsevier 2019c). It is not the scope of this paper to describe these in detail, but where appropriate they will be briefly discussed.

Under the purview of the University Grant Commission (UGC) of Sri Lanka there are fifteen state universities (Table 1). Periodic evaluation of its research productivity is an important factor for all these state universities. Only a few studies (Aponsu 2017, Fernando, Hemachandra and Muthulingam 2015 and Senaratne 2015) have attempted to identify the prevailing trends but none of them have done a detailed quantitative analysis 
of the research productivity of the State universities of Sri Lanka, therefore this study is an attempt to fill this gap to some extent.

Table 1. State universities of Sri Lanka under the purview of UGC

\begin{tabular}{|c|c|c|c|c|c|}
\hline University & $\begin{array}{c}\text { No. of } \\
\text { Faculti } \\
\text { es } \\
*\end{array}$ & $\begin{array}{c}\text { No. of } \\
\text { Institutes }\end{array}$ & $\begin{array}{c}\text { Total } \\
\text { Undergraduates } \\
* *\end{array}$ & $\begin{array}{c}\text { Total } \\
\text { Postgraduates }\end{array}$ & $\begin{array}{c}\text { Total } \\
\text { Academic } \\
\text { Staff }\end{array}$ \\
\hline $\begin{array}{l}\text { University of Colombo } \\
\text { (UoC) }\end{array}$ & 9 & 7 & 10,918 & 12,649 & 605 \\
\hline $\begin{array}{l}\text { University of Peradeniya } \\
\text { (UoP) }\end{array}$ & 9 & 3 & 10,561 & 7,623 & 822 \\
\hline $\begin{array}{l}\text { University of Sri } \\
\text { Jayawardenepura (UoSJP) }\end{array}$ & 7 & 1 & 11,841 & 2,091 & 591 \\
\hline $\begin{array}{l}\text { University of Kelaniya } \\
\text { (UoK) }\end{array}$ & 7 & 3 & 10,446 & 3,801 & 563 \\
\hline $\begin{array}{l}\text { University of Moratuwa } \\
\text { (UoM) }\end{array}$ & 5 & 1 & 7,343 & 3,847 & 344 \\
\hline University of Jaffna (UoJ) & 10 & 1 & 9,102 & 651 & 430 \\
\hline University of Ruhuna (UoR) & 10 & 0 & 7,030 & 544 & 508 \\
\hline $\begin{array}{l}\text { Open University of Sri } \\
\text { Lanka (OUSL) }\end{array}$ & 5 & 1 & 24,346 & 7,912 & 223 \\
\hline $\begin{array}{l}\text { Eastern University of Sri } \\
\text { Lanka (EUSL) }\end{array}$ & 8 & 0 & 4,596 & 172 & 151 \\
\hline $\begin{array}{l}\text { South eastern University of } \\
\text { Sri Lanka (SEUSL) }\end{array}$ & 6 & 0 & 4,270 & 338 & 243 \\
\hline $\begin{array}{l}\text { Rajarata University of Sri } \\
\text { Lanka (RUSL) }\end{array}$ & 6 & 0 & 4,675 & 321 & 211 \\
\hline $\begin{array}{l}\text { Sabaragamuwa University } \\
\text { of Sri Lanka (SUSL) }\end{array}$ & 5 & 0 & 4,194 & 154 & 160 \\
\hline $\begin{array}{l}\text { Wayamba University of Sri } \\
\text { Lanka (WUSL) }\end{array}$ & 6 & 0 & 3,527 & 435 & 134 \\
\hline $\begin{array}{l}\text { Uva Wellassa University of } \\
\text { Sri Lanka (UWUSL) }\end{array}$ & 4 & 0 & 2,254 & 3 & 110 \\
\hline $\begin{array}{l}\text { University of Visual and } \\
\text { Performing Arts (UVPA) }\end{array}$ & 4 & 0 & 2,217 & 96 & 301 \\
\hline Higher Education Institutes & & & & & 270 \\
\hline Total & 101 & 17 & 117,320 & 40,637 & 5,666 \\
\hline
\end{tabular}

Source: University Grants Commission (2018) p.1-18

*Including faculties in affiliated campuses

**Including students of affiliated institutes / Campuses but excluding external students 


\section{Research Objectives}

The objective of this study is to assess the research productivity of the state universities of Sri Lanka using SciVal and the contribution of the university libraries towards the excellence of research productivity.

Following four Research Questions (RQs) were formulated to support achieving the objectives;

RQ 1 - What is the scholarly output of Sri Lankan State Universities?

RQ 2 - What is the Citation Impact of this scholarly output?

RQ 3 - What is the nature of collaborations in the scholarly output?

RQ 4 - What services are provided by the Sri Lankan State university libraries to support the research productivity of their universities?

\section{Literature Review}

Since this paper takes a bibliometric approach to measuring the research productivity using SciVal, only the literature related to bibliometric approach has been reviewed here.

The measurement of research productivity using bibliometric indicators reveal that there is no consensus, but certain indicators are used more often than the others. Total number of documents published by an entity has been identified by many researchers (Bornmann \& Leydesdorff, 2013; Erfanmanesh \& Nojavan, 2016; Erfanmanesh, Tahira \& Abrizah 2017; Gadhoum \& Karam, 2016; King, 2004; Nejati \& Jenab 2010 and Tafreshi, Imani \& Ghashlag, 2013). Number of Citations (Erfanmanesh, Tahira \& Abrizah 2017; and Smith, Weinberger, Bruna, \& Allesina, 2014), and international collaboration (Erfanmanesh, Tahira \& Abrizah, 2017) are also used to measure research productivity.

Erfanmanesh, Tahira and Abrizah (2017) have studied the publication success of 102 countries in two aspects - the quantity of the country's journals indexed in Scopus and the total productivity of that country in Scopus database covering a period from 2005 to 2014. They conclude that the scientific productivity of a country depends significantly on the number of journals indexed from that country in citation databases. Further, Tafreshi, Imani \& Ghashlag (2013) have used submitting articles, book 
writing and translation, thesis and dissertation supervision, administrativescientific services, judgment in relation to articles and research plans, innovation and invention and having research plans, to measure research productivity in Iranian universities.

\section{Research productivity of Sri Lankan state universities}

There are several bibliometric studies on research productivity of Sri Lankan state universities, based on Scopus and Web of Science (WoS) but no evidence of the use of SciVal. Pethiyagoda (2005) claims that only 234 papers are published in indexed journals and the majority of them by the Sri Lankan nationals working in foreign laboratories; however the author does not mention the source of these numbers. The factors that affect the productivity have been identified as poor syllabi implemented by inadequately motivated and qualified teachers, outdated instructional techniques, undue emphasis on examinations, restricted access to English language and academic promotion schemes that overlook quality for quantity. Mehbuba and Rousseau (2010), have established that Sri Lanka, is the scientifically strongest of Bangladesh, India, Pakistan and Sri Lanka. They based their comments on the number of publications and the evolution of country $h$-indices from 1973-2007. Yet, they identified two decreasing trends; a slow decrease from 1973-1997 and a faster decrease from 1998 to 2007.

Pratheepan (2011), established that of 3370 publications contributed by Sri Lanka, 2442 (72.46\%) were from the Sri Lankan universities, and UoP recorded the highest number of publications (926), citation count (5757) and accommodates 14 of 30 top Sri Lankan authors (those who have published the highest number of papers from Sri Lanka). UoC followed with 555 publications and 3910 citations, both universities had an h-index of 30 . UoK, UoR, UoSJP and UoM have followed respectively while the research productivity of the other universities, was not significant. Gupta (2012) concludes that Sri Lanka needs to increase research productivity, output and quality of research, by investing more on Research \& Development expenditure, increasing more qualified manpower and international collaboration and by modernizing and strengthening its research infrastructure. Navaneethakrishnan (2013) established that 8694 documents 
of 11 types were published and of this 6671 were articles and that UoP recorded the highest number of publications while medicine and science are the most represented disciplines. UoC and UoK have recorded the second and third highest contributions respectively while the author does not mention any other universities.

Navaneethakrishnan (2014), established that in social science and humanities, 1795 documents of 11 types have been authored by 3521 authors and of that $77 \%$ are articles and the highest number (169) has been published in 2010 followed by 2012 (167), 2011 (151) and 2009 (150). It was also established that $65 \%$ of the publications had two or more authors while $35 \%$ had only a single author. Of the collaborating countries, USA (15.93\%), UK (7.41\%) and Australia (4.23\%) were prominent. Pratheepan and Weerasooriya (2015) established that, Faculties of science is the best performer with the mean h-index of 5.55, followed by medicine (5.24), engineering (3.81), agriculture (3.76), management (2.74) and arts (2.62). It was further established that UoP was most productive in agriculture, arts, science and engineering while in medicine, UoK was the best with a mean h-index with 6.85 . The results also have indicated that the productivity of professors in arts except in UoP was very poor. In a study of Erfanmanesh, Tahira and Abrizah (2017), Sri Lanka was depicted in the $69^{\text {th }}$ place of 102 countries, with 6 journals indexed in Scopus. Although this study does not discuss about Sri Lanka any further, this figure is sufficient to conclude that the research productivity and the availability of quality journals of the country are not impressive. Chandani and Wijayasundara (2019), covering 1989-2018 in Scopus related to UoSJP, established that 869 documents in 7 types have been published during the period.

\section{Role of libraries in supporting research}

"The digital revolution has changed the relationship between libraries and researchers, many of whom do not use the physical library. As one librarian said, "the more we do to make access quick, seamless and easy, the more invisible we make ourselves". Libraries are becoming alert to their separation from researchers, and are trying to find ways to reconnect with them, and to fill the gaps in their knowledge 
and understanding of researchers' needs." (Research Information Network \& Research Libraries UK 2011: 7).

Growing ubiquity of social media, rise of data-driven learning and assessment, shift of students from consumers to creators, flipped classes, game and gamification, self-capturing of data through wearable devices (Khumbar, 2014) demands a shift in the service paradigm. The perpetual role of providing scholarly access to relevant information resources is changing to provision of online access to materials. Therefore, librarians' need to collaborate with the faculty, use of advanced technologies to provide information, have a key role as educators, and they need to shape their skills and knowledge to meet these new demands (Mwaniki, 2018). Aslam (2017) identified several trends which challenges the libraries: Open access material, changing model of scholarly communication, need for redesigning library space, competition from other information providers, shrinking budgets and diverse population engaging in learning which requires diverse services.

Research Information Network and Research Libraries UK (2011: 8) claim that "Libraries are changing and the value they provide will change too. The need to demonstrate value will endure and should not be underestimated. Arguing the case for libraries may get harder as the traditional role of libraries in providing access to content-the role most frequently mentioned and valued by researchers and senior managers-continues to become less visible." As pointed out by Delaney and Bates (2015: 30), "the core argument is that academic libraries need to continue to adapt their roles and develop stronger relationships across the university in order to maintain and promote their relevance to all stakeholders."

In response to the challenges imposed by these changing trends in higher education, researchers have identified several responsive measures that can be adopted by the librarians. Support in Research Data Management and bibliometric support services to measure the research impact have been stressed by many researchers (Brown, Alvey, Danilova, Morgan \& Thomas, 2018; Corrall, Kennan, \& Afzal, 2013; Haddow \& Mamtora, 2017; Keller, 2015; Kennan, Corrall, \& Afzal, 2014; Sewell \& Kingsley, 2017; Shelley \& 
Jackson, 2018; Si, Zeng, Guo, and Zhuang, 2019 and Zhao, 2014). Open access material related services and training in using related tools (i.e. SHERPA/ Romeo) have been identified as another change to be adopted by the academic libraries (Keller, 2015; Sewell \& Kingsley 2017; Si et.al. 2019; Zhao 2014). Digitizing and digital curation, creating and managing Institutional Repositories (Brown et.al. 2018; Keller, 2015 \& Zhao, 2014), supporting scholarly publication (Brown et.al. 2018; Si et.al. 2019) and guiding researches by providing consultancy and training (Keller, 2015; Haddow \& Mamtora, 2017; Si et.al. 2019) are the other initiatives identified as the research support services that need to be offered by the libraries in order to cater to the changing needs of the higher education.

\section{Methodology}

\section{Selection of Sample}

Four international university ranking systems that use research as one of the components in their ranking methodology were used to identify the State universities included in their ranking lists. These four ranking systems were the Times Higher Education (THE), Quacquerelli Symonds (QS), SCImago Institutional Ranking (SIR) and the University Ranking by Academic Performance (URAP) and respectively they assign $62.5 \%, 20 \%, 80 \%$ and $100 \%$ to research in calculating their scores. Table 2 illustrates the Sri Lankan State universities which appeared in the World and Asian ranking lists of different ranking systems in 2018. The variations in the number of universities included in different ranking systems can be attributed to the variations in their calculation systems.

The highest number of Sri Lankan State universities has been listed by SIR in both World and Asian contexts. Out of these, UoC, UoP, UoK, UoR and UoSJP (excluding UoM) were selected as the sample to analyse further using SciVal. UoM was excluded since it only represents one discipline while other five universities represent both STEM (Science, Technology, Engineering and Medicine) and HEMS (Humanities, Education, Management and Social Sciences) domains with a wider inclusion of researchers. 
Table 2. Appearance of Sri Lankan State Universities in International University Ranking Systems in 2018

\begin{tabular}{|c|c|c|c|}
\hline \multirow[t]{2}{*}{ Ranking System } & \multirow{2}{*}{$\begin{array}{l}\text { Weight Assigned to } \\
\text { Research } \\
\text { component out of } \\
\text { total score }\end{array}$} & \multicolumn{2}{|c|}{2018} \\
\hline & & World Rank & Asian Rank \\
\hline $\begin{array}{l}\text { Times Higher } \\
\text { Education (THE) }\end{array}$ & $62.5 \%$ & $\begin{array}{l}\text { Uoc }(801- \\
1000)\end{array}$ & UoC (301-350) \\
\hline $\begin{array}{l}\text { Quacquerelli Symonds } \\
\text { (QS) }\end{array}$ & $20 \%$ & $\begin{array}{l}\text { UoC (751- } \\
800)\end{array}$ & $\begin{array}{l}\text { UoC (156) } \\
\text { UoP (242) } \\
\text { UoM (291-300) }\end{array}$ \\
\hline $\begin{array}{l}\text { SCImago Institutional } \\
\text { Ranking (SIR) }\end{array}$ & $80 \%$ & $\begin{array}{l}\text { UoC (703) } \\
\text { UoP (672) } \\
\text { UoSJP (694) } \\
\text { UoM (698) } \\
\text { UoR(738) } \\
\text { UoK (746) }\end{array}$ & $\begin{array}{l}\text { UoC (303) } \\
\text { UoP (272) } \\
\text { UoSJP (294) } \\
\text { UoM (298) } \\
\text { UoR (338) } \\
\text { UoK (346) }\end{array}$ \\
\hline $\begin{array}{l}\text { University Ranking by } \\
\text { Academic } \\
\text { Performance (URAP) }\end{array}$ & $100 \%$ & UoP (1334) & UoP (416) \\
\hline $\begin{array}{l}\text { Sources: https://www.time } \\
\text { https://www.topuniversiti } \\
\text { https://www.topuniversiti }\end{array}$ & $\begin{array}{l}\text { highereducation.com, } \\
\text { com/university-rankings } \\
\text { com/university-rankings }\end{array}$ & . & ings/2018 \\
\hline
\end{tabular}

\section{Data gathering}

Quantitative data were gathered from SciVal to address RQ1, RQ2 and RQ3 while qualitative data were gathered from 15 University Librarians to address RQ4.

A two-week trial access to SCiVal was provided to UoC in February 2019 and during this period three metrics were selected from SciVal to measure the research productivity of the selected universities. Primary data related to these three metrics namely, scholarly output, citation impact and collaboration were collected using the "Overall Research Performances" feature of SciVal. In extracting data for the study, no Subject Area or Publication-Type filters were used. The period covered in the analysis was 2015-2018, and the data were downloaded on $14^{\text {th }}$ February 2019 . The data 
source of SciVal which was Scopus has been last updated on $18^{\text {th }}$ January 2019 according to the publisher. A description of the three main criteria and their related metrics used by SciVal to measure the research productivity of the universities is given below.

\section{Scholarly Output}

"Scholarly output in SciVal indicates the prolificacy of an entity: how many publications does an entity have indexed in Scopus?" (Elsevier 2019c: 37). To measure Scholarly Output, SciVal uses six criteria; number of publications, scholarly output growth, number of authors, author growth (\%, publications in top journal percentile and views. While the first four criteria are straightforward, the publications in top journal percentile indicate the extent to which an entity's publications are present in the most-cited journals in the data universe; how many publications are in the top $1 \%, 5 \%, 10 \%$ or $25 \%$ of the most-cited journals indexed by Scopus." (Elsevier 2019c: 49). "The Most cited-journals are defined by the journal metrics CitScore, SNIP (Source Normalised Impact per paper) or SJR (SCImago Journal Rank). Views counts in SciVal are generated from usage data in Scopus. The metric is the sum of abstract views and clicks on the link to view from both subscribed and trial customers." (Elsevier 2019c: 41).

\section{Citation Impact}

"Citation Impact metrics indicate the influence of an entity's output, and is useful to benchmark the visibility of entities of similar size and that fall into similar disciplines, provide impressive figures to showcase the productivity of entities that are large in comparison to a group of peers and showcase the productivity of entities that have published a few noticeably highly cited papers." (Elsevier, 2019c: 45). To measure Citation Impact, SciVal uses five metrics; Citation Count, Citations per publication, Field-Weighted Citation Impact which indicates "how do the citations received by this entity's publications compare with the world average." (Elsevier 2029c: 46), Outputs in Top Citation Percentile which indicates the extent to which an entity's publications are present in the most-cited percentiles of a data universe: how many publications are in the top $1 \%, 5 \%, 10 \%$, or $25 \%$ of the most-cited publications." (Elsevier 2019c: 48) and " $h 5$-indices which uses a 5 year publication and citation window on the standard $h$-index calculation and as 
such can be used to fairly track the metric over time in the Benchmarking module." (Elsevier 2019c: 40).

\section{Collaboration}

"Collaboration in SciVal indicates the extent to which an entity's publications have international, national, or institutional co-authorship, and single authorship. Each publication is assigned 101 of 4 mutually exclusive collaboration types, based on its affiliation information: international, national, or institutional or single authorship... a single collaboration types is assigned to ensure that the sum of an entity's publications across the 4 categories adds up to $100 \%$ of the publications with the necessary affiliation information." (Elsevier 2019c: 32-33). Two metrics are used to calculate Collaboration;

i. "International Collaboration is the extent to which university publications have international co-authorship

ii. Academic/Corporate Collaboration which indicates the degree of the degree of collaboration between academic and corporate affiliations." (Elsevier 2019c:35).

Table 3. Metrics and Criteria used to address the Research Questions

RQ 1 - What is the scholarly output of Sri

Lankan State Universities?
RQ 2 - What is the

Citation Impact of this scholarly output?
RQ 3 - What is

the nature of collaborations in the scholarly output?
RQ 4 - What services are provided by the Sri Lankan State university libraries to support the research productivity of their universities?

\begin{tabular}{|c|c|c|c|}
\hline $\begin{array}{c}\text { Scholarly output } \\
\text { Metric }\end{array}$ & $\begin{array}{c}\text { Citation Impact } \\
\text { Metric }\end{array}$ & $\begin{array}{c}\text { Collaboration } \\
\text { Metric }\end{array}$ & $\begin{array}{c}\text { Research support } \\
\text { Services }\end{array}$ \\
\hline \multicolumn{3}{|c|}{ Criteria which provides quantitative data } & Qualitative Data \\
\hline $\begin{array}{l}\text { - Number of } \\
\text { publications } \\
\text { - Scholarly output } \\
\text { growth } \\
\text { - Number of authors } \\
\text { - Author growth (\%), } \\
\text { - Publications in top } \\
\text { journal percentile } \\
\text { (top } 10 \% \text { by Cite } \\
\text { Score) } \\
\text { - Views }\end{array}$ & $\begin{array}{l}\text { - Citation count } \\
\text { - Citations per } \\
\text { publication } \\
\text { - Field-weighted } \\
\text { citation impact. } \\
\text { - Output in top } \\
\text { citation percentile } \\
\text { (top } 10 \%), \\
\text { - } h 5 \text {-indices }\end{array}$ & $\begin{array}{l}\text { - International } \\
\text { collaboration } \\
\text { - Academic / } \\
\text { corporate } \\
\text { collaboration }\end{array}$ & $\begin{array}{l}\text { Librarians of } 15 \\
\text { State universities } \\
\text { under the purview } \\
\text { of the UGC were } \\
\text { asked to explain } \\
\text { the services they } \\
\text { provide to support } \\
\text { the research } \\
\text { productivity of } \\
\text { their universities in } \\
\text { an open-ended } \\
\text { question. }\end{array}$ \\
\hline
\end{tabular}


In order to gather data on library services that support research, an openended question was e-mailed to 15 Librarians/Acting Librarians. (To avoid any bias a Senior Assistant Librarian was asked to respond on behalf of the authors' university). The Criteria and metrics used to address RQ1 to RQ4 are summarized in Table 3.

\section{Limitations of the study}

Firstly, the research productivity of the universities was based entirely on the publications indexed in Scopus which is used by SciVal to produce analytics. Therefore the publications of the universities not indexed by Scopus, have not been included in the SciVal calculations. This can be considered as a limitation of the study as the true research productivity of a university could be greater than what is depicted in Scopus or SciVal. Secondly, only the University Librarians were contacted to gather data and any in-depth study was not conducted to establish the statistical correlation between the services offered and the research productivity due to time limitation. Therefore the accuracy of the findings is limited to the responses given by the Librarians. Thirdly, due to lack of previously published empirical data on research productivity of the State universities, and the time and resource constraints to gather original supporting data, this paper does not attempt to address "why" the research productivity of universities studied has taken that pattern. However, the authors believe that the study would help the policy makers, academics and librarians to understand the research productivity scenario of the Sri Lankan State universities to a significant extent. This study also would help fill the void of literature in research productivity of Sri Lankan State universities, to some extent.

\section{Findings}

\section{Scholarly Output}

As depicted in the Table 4, a total of 4723 publications have been recorded during the study period, with UoC (1494) and UoP (1482) contributing the highest numbers while UoSJP and UoK contributing the least number. UoSJP has recorded the highest percentage of the growth of publications across the study period followed by UoC. UoK and UoP have recorded the lowest growth percentages. While UoC shows an increase in publications up to 2017 , it has stagnated during 2017 to 2018 . UoP indicates a growth from 
2015 to 2016 but since then a slow decline in the numbers. It depicts for UoR, UoK and UoSJP, a slow but continuous growth in the numbers across the years (Figure 1).

Table 4. Number and growth of Scholarly Publications

\begin{tabular}{|c|c|c|c|c|c|c|}
\hline University & 2015 & 2016 & 2017 & 2018 & Total & Growth (\%) \\
\hline UoC & 279 & 350 & 430 & 435 & 1494 & 54.1 \\
\hline UoK & 104 & 115 & 127 & 162 & 508 & 22.1 \\
\hline UoP & 317 & 396 & 387 & 382 & 1482 & 22.1 \\
\hline UoR & 137 & 182 & 197 & 231 & 747 & 43.8 \\
\hline UoSJP & 79 & 116 & 126 & 171 & 492 & 59.5 \\
\hline Total & 916 & 1159 & 1267 & 1381 & 4723 & - \\
\hline
\end{tabular}

Source: SciVal

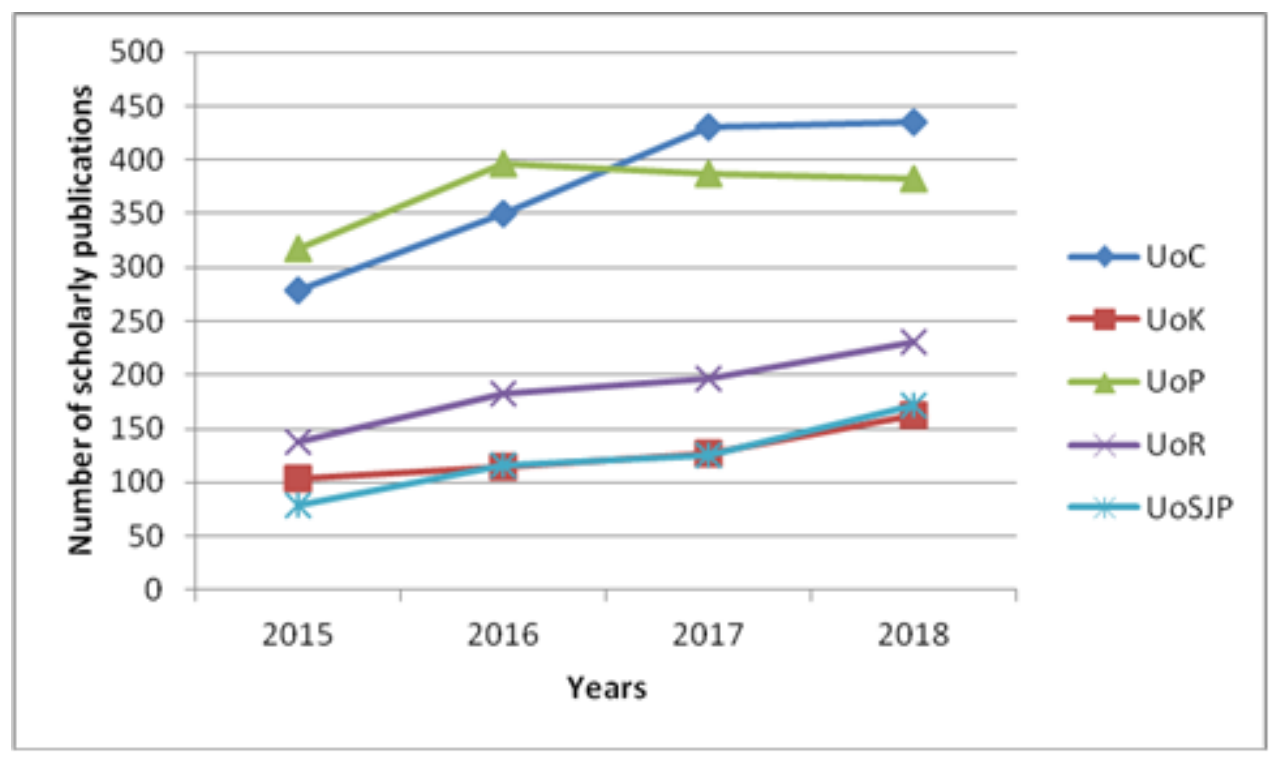

Figure 1. Number of Scholarly Publications

A total of 3831 authors have been recorded with the highest number of authors coming from UoC and UoP while the lowest number coming from UoK. Highest percentage of growth in number of authors is recorded by UoC while the lowest growth is recorded by UoP (Table 5). It depicts a continuous growth of the number of authors from UoC until 2017, but it has almost stagnated between 2017 and 2018. It depicts a sharp growth from 
2015 to 2016 in UoP, but it has dropped by 2017, to pick up by 2018 but not up to the level that existed in 2017. UoK, UoR and USJP show a slow growth with a decline in 2017 (Figure 2).

Table 5. Number and Growth of Authors

\begin{tabular}{|c|c|c|c|c|c|c|}
\hline University & 2015 & 2016 & 2017 & 2018 & Total & $\begin{array}{c}\text { Growth } \\
(\%)\end{array}$ \\
\hline UoC & 330 & 423 & 555 & 553 & 1280 & 68.2 \\
\hline UoK & 114 & 131 & 160 & 176 & 382 & 40.4 \\
\hline UoP & 389 & 539 & 488 & 521 & 1258 & 25.4 \\
\hline UoR & 122 & 156 & 155 & 189 & 455 & 27 \\
\hline UoSJP & 114 & 177 & 161 & 212 & 456 & 41.2 \\
\hline Total & 1069 & 1426 & 1519 & 1651 & 3831 & \\
\hline
\end{tabular}

Source: SciVal

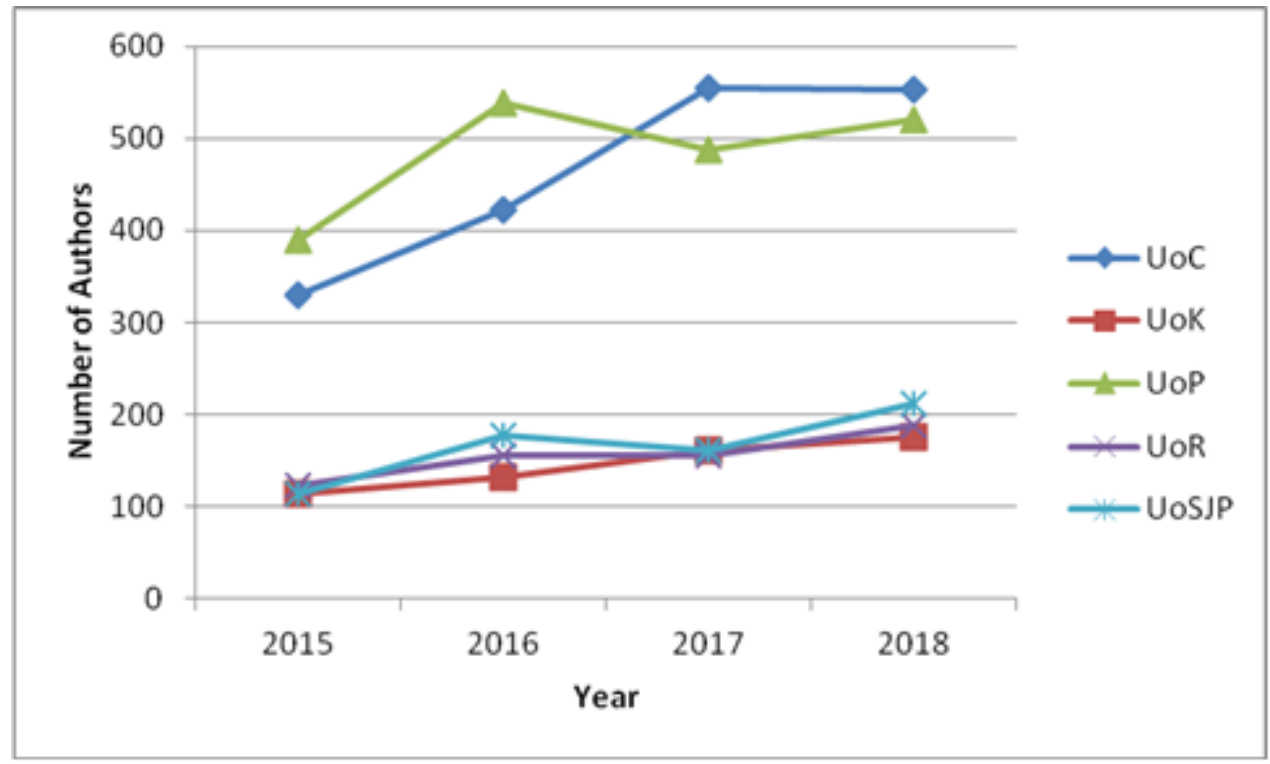

Figure 2. Number of Authors

UoR records the highest percentile of publications in top journal percentile at 54.5 which is considerably higher than the rates of other four universities while UoC recording the lowest at 16.5 (Table 6). Yet, the numbers have increased up to 2017 but have decreased from 2017 to 2018. UoC shows a decrease from 2015 to 2016, an increase from 2016 to 2017 but a decrease again from 2017 to 2018. UoP also echoes this same pattern although the 
decrease in 2016 is, as not sharp as in UoC. Publications of UoK in top journal percentile have been high in 2015, dropped in 2016, but slowly increased across 2016 and 2017. Figure 3 depicts a drop from 2015 to 2016 in UoSJP, an increase in 2017 and a slight decrease in 2018.

Table 6. Publications in top journal percentile

\begin{tabular}{|c|c|c|c|c|c|}
\hline University & 2015 & 2016 & 2017 & 2018 & Overall \\
\hline UoC & 18.6 & 18.1 & 13.8 & 16.7 & 16.5 \\
\hline UoK & 29 & 19.4 & 23.5 & 25.7 & 24.5 \\
\hline UoP & 25.5 & 23.4 & 26.2 & 20.2 & 23.8 \\
\hline UoR & 46.8 & 56.8 & 60.2 & 52.6 & 54.5 \\
\hline UoSJP & 25 & 18.4 & 24.1 & 20.3 & 21.5 \\
\hline
\end{tabular}

Source: SciVal

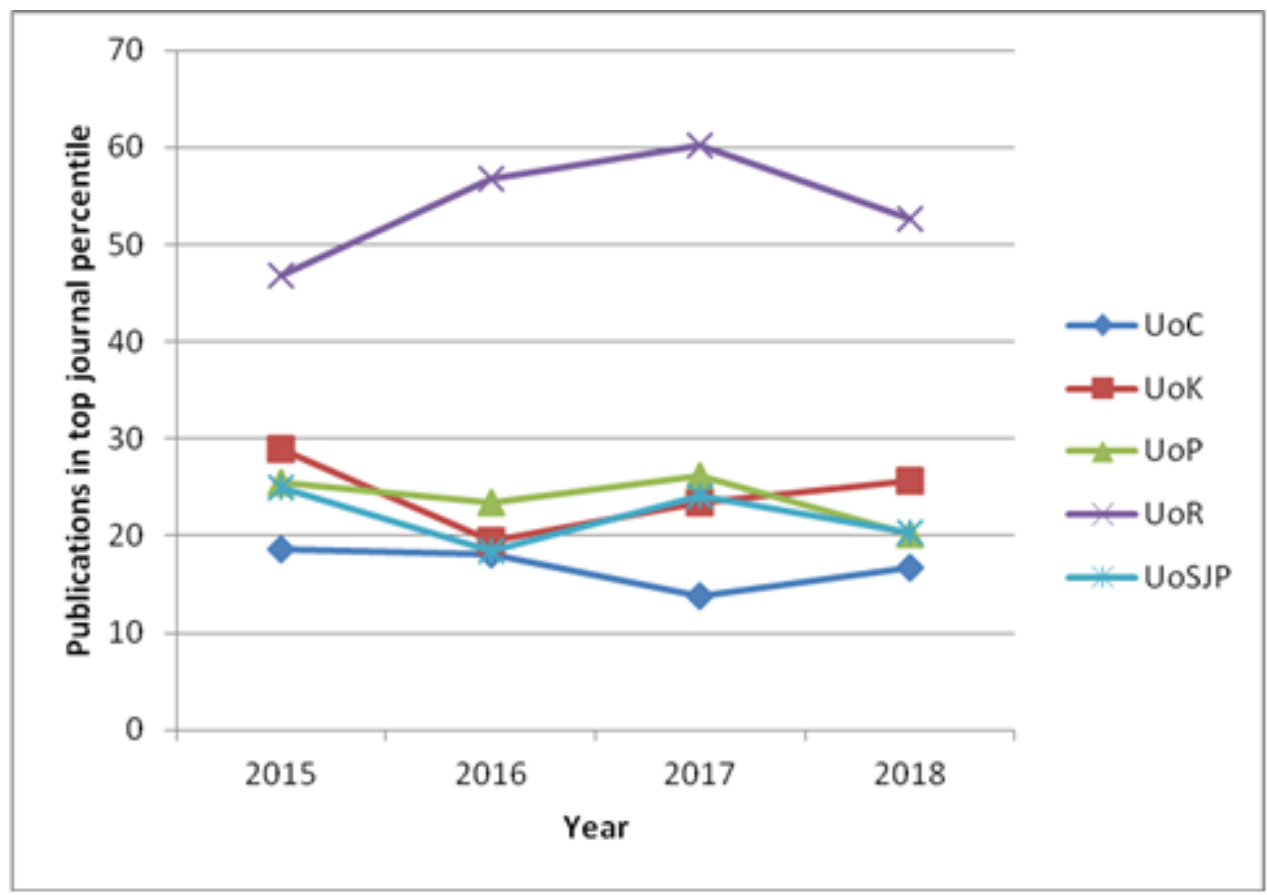

Figure 3. Publications in top journal percentile

During the study period a total of 129913 views were evident, with UoR (53803) recording the highest number of views of all five universities while UoSJP and UoK recording the lowest. This trend has been maintained in overall views per publication, with UoR recording the highest views per publication followed by UoP. UoSJP and UoC recorded the lowest overall 
views per publication respectively (Table 7). The pattern of views illustrate that the views of UoP has dropped sharply from 2015 to 2018 while views for UoR had a sharp increase from 2015 to 2016 and a slow increase in 2017 and a sharp drop in 2018. Views for UoC remained low with a slow decline from 2016 to 2018 while the views of publications of UoK and UoSJP remained low but steady across the study period (Figure 4).

Table 7. Views

\begin{tabular}{lrrrrrr}
\hline University & $\mathbf{2 0 1 5}$ & $\mathbf{2 0 1 6}$ & $\mathbf{2 0 1 7}$ & $\mathbf{2 0 1 8}$ & Overall & $\begin{array}{c}\text { Overall Views } \\
\text { Per Publication }\end{array}$ \\
\hline UoC & 4616 & 5343 & 4472 & 3364 & 17795 & 11.9 \\
UoK & 2045 & 2009 & 2118 & 1494 & 7666 & 15.1 \\
UoP & 14970 & 13870 & 10379 & 4254 & 43473 & 29.3 \\
UoR & 8991 & 16171 & 17463 & 11178 & 53803 & 72 \\
UoSJP & 1459 & 2157 & 1766 & 1794 & 7176 & 14.6 \\
Total & $\mathbf{3 2 0 8 1}$ & $\mathbf{3 9 5 5 0}$ & $\mathbf{3 6 1 9 8}$ & $\mathbf{2 2 0 8 4}$ & $\mathbf{1 2 9 9 1 3}$ & \\
\hline
\end{tabular}

Source: SciVal

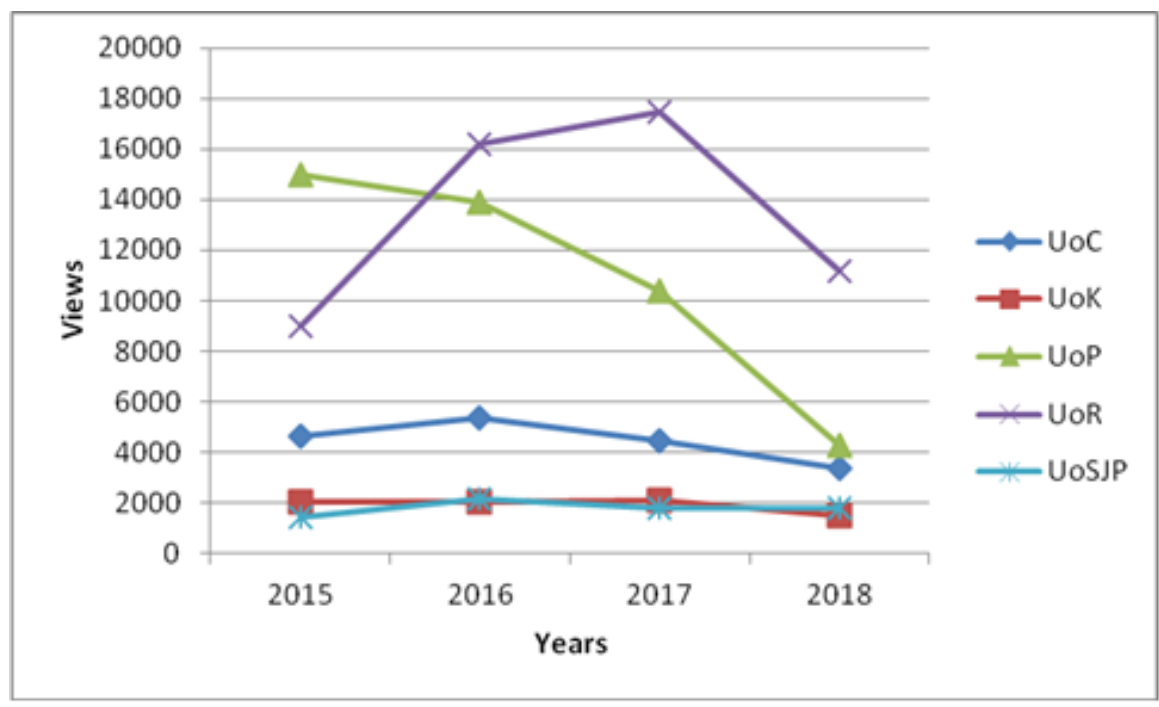

Figure 4. Views

\section{Citation Impact}

Following sections present the findings on; Citation Count and h5-index, Field-weighted citation impact, and Output in top citation percentile (top $10 \%$ ). During the period studied, UoP has reported the highest citation count (18322) while UoSJP has reported the lowest citation (1257) count (Table 8). 
Table 8. Citation count

\begin{tabular}{lrrrrrc}
\hline University & $\mathbf{2 0 1 5}$ & \multicolumn{1}{c}{$\mathbf{2 0 1 6}$} & \multicolumn{1}{c}{$\mathbf{2 0 1 7}$} & $\mathbf{2 0 1 8}$ & Overall & h5-index \\
\hline UoC & 1596 & 1300 & 802 & 240 & 3938 & 26 \\
UoK & 1213 & 477 & 439 & 110 & 2239 & 23 \\
UoP & 9322 & 5329 & 3407 & 264 & 18322 & 38 \\
UoR & 3087 & 2300 & 1351 & 520 & 7258 & 39 \\
UoSJP & 431 & 331 & 412 & 83 & 1257 & 17 \\
Total & $\mathbf{1 5 6 4 9}$ & $\mathbf{9 7 3 7}$ & $\mathbf{6 4 1 1}$ & $\mathbf{1 2 1 7}$ & $\mathbf{3 3 0 1 4}$ & \\
\hline
\end{tabular}

Source: SciVal

Figure 5 indicates the trend of citation count with a sharp drop.

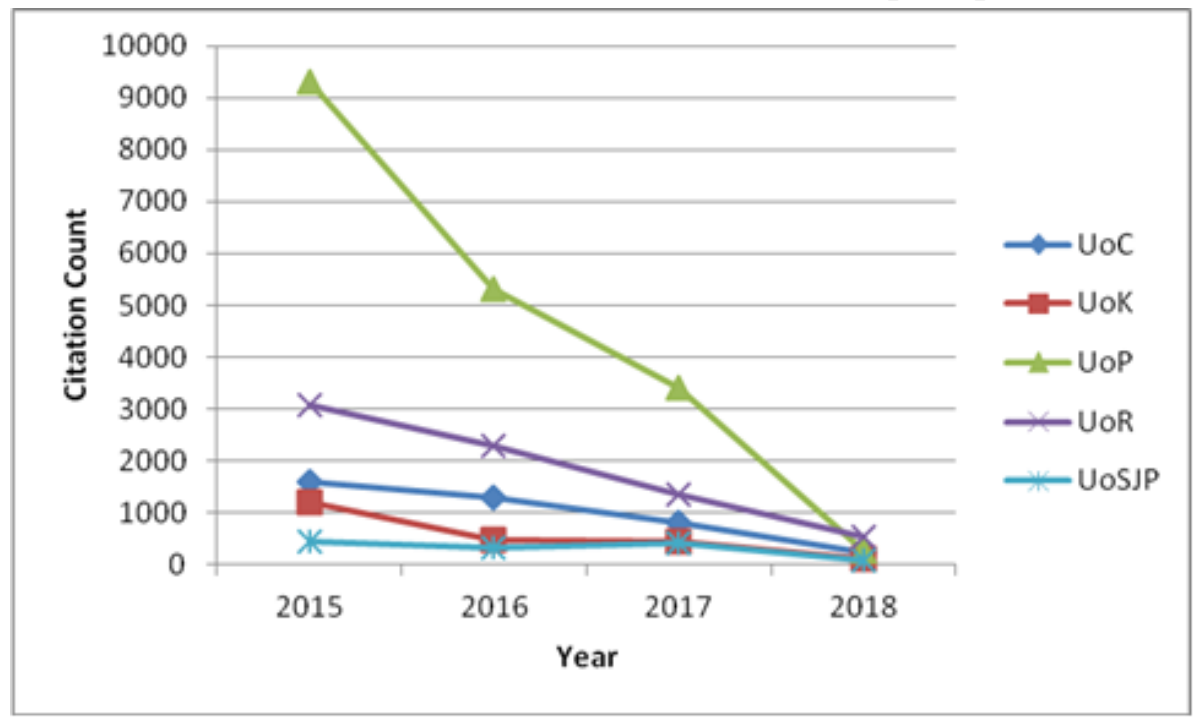

Figure 5. Citation count

UoR records the highest $h 5$-index of 39 while UoSJP records the lowest of 17 (Table 8). Overall, UoP shows the highest Field-Weighted Citation Impact (FWCI) at 3.18, while UoC and UoSJP showing the lowest at 0.8 (Table 9).

Table 9. Field-weighted citation impact

\begin{tabular}{|c|c|c|c|c|c|}
\hline University & 2015 & 2016 & 2017 & 2018 & Overall \\
\hline UoC & 0.85 & 0.76 & 0.78 & 0.82 & 0.8 \\
\hline UoK & 1.39 & 0.78 & 1.08 & 0.95 & 1.03 \\
\hline UoP & 5.24 & 3.56 & 3.22 & 1.03 & 3.18 \\
\hline UoR & 2.37 & 1.88 & 1.89 & 2.02 & 2.02 \\
\hline UoSJP & 0.87 & 0.57 & 1.14 & 0.66 & 0.8 \\
\hline
\end{tabular}

Source: SciVal 


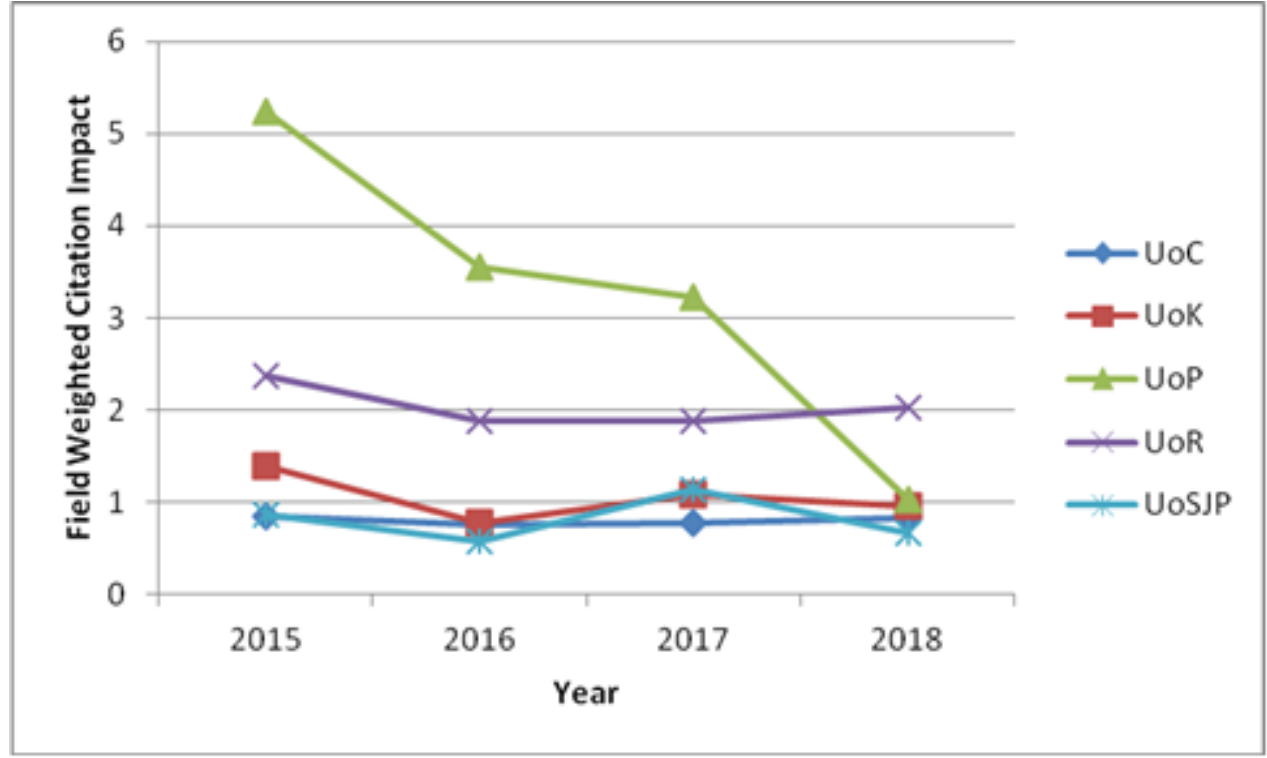

Figure 6. Field-weighted Citation Impact

Findings indicated that $32.5 \%$ of UoR's publications were present in mostcited publications while publications of UoSJP and UoC were in the lowest percentiles (Table 10).

Table 10. Output in top citation percentile

\begin{tabular}{lrrrrr}
\hline \multicolumn{1}{c}{ University } & $\mathbf{2 0 1 5}$ & \multicolumn{1}{c}{$\mathbf{2 0 1 6}$} & $\mathbf{2 0 1 7}$ & $\mathbf{2 0 1 8}$ & \multicolumn{1}{c}{ Overall } \\
\hline UoC & 9 & 8 & 5.6 & 12.6 & 8.8 \\
UoK & 13.5 & 8.7 & 7.9 & 11.1 & 10.2 \\
UoP & 12 & 12.1 & 12.7 & 13.6 & 12.6 \\
UoR & 29.2 & 30.8 & 34 & 34.6 & 32.5 \\
UoSJP & 5.1 & 6 & 9.5 & 10.5 & 8.3 \\
\hline
\end{tabular}

Source: SciVal

UoR seems to maintain a significant difference from other universities in the output in top citation percentile though with a trend of a slow growth across the years. For UoK, it depicts a slow decline and gradual increase by 2018 while UoP has maintained the trend almost at the same level with a slight increase in 2018. UoC shows a decline towards 2017 and a sharp increase in 2018 while UoSJP showing a continuous increase across the study period (Figure 7) 


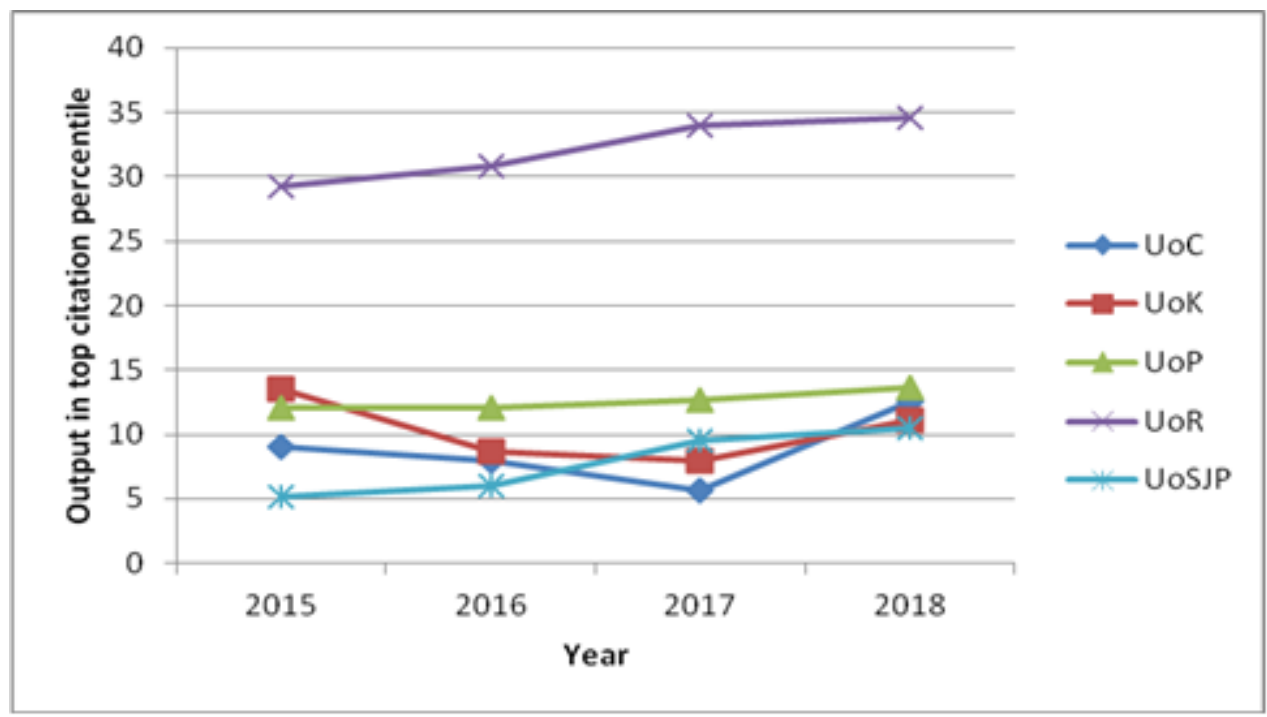

Figure 7. Output in top citation percentile

UoP records the overall highest citations per publication at 12.4 while UoC and UoSJP record the lowest at 2.6 (Table 11).

\section{Table 11. Citations per publication}

\begin{tabular}{|c|c|c|c|c|c|}
\hline University & 2015 & 2016 & 2017 & 2018 & Overall \\
\hline UoC & 5.7 & 3.7 & 1.9 & 0.6 & 2.6 \\
\hline UoK & 11.7 & 4.1 & 3.5 & 0.7 & 4.4 \\
\hline UoP & 29.4 & 13.5 & 8.8 & 0.7 & 12.4 \\
\hline UoR & 22.5 & 12.6 & 6.9 & 2.3 & 9.7 \\
\hline UoSJP & 5.5 & 2.9 & 3.3 & 0.5 & 2.6 \\
\hline
\end{tabular}

Source: SciVal

\section{Collaboration}

International collaboration and Academic/Corporate Collaboration are the metrics used to measure Collaboration. UoR records the highest overall international collaboration during the period of study at 74.4 and UoSJP records the lowest at 43.1 (Table 12). 
Table 12. International Collaboration

\begin{tabular}{llllll}
\hline University & $\mathbf{2 0 1 5}$ & $\mathbf{2 0 1 6}$ & $\mathbf{2 0 1 7}$ & $\mathbf{2 0 1 8}$ & Overall \\
\hline UoC & 48.4 & 43.4 & 44.4 & 46.7 & 45.6 \\
UoK & 50 & 42.6 & 45.7 & 58.6 & 50 \\
UoP & 57.1 & 50.5 & 58.4 & 55.8 & 55.3 \\
UoR & 73 & 72 & 75.1 & 76.6 & 74.4 \\
UoSJP & 41.8 & 37.1 & 40.5 & 49.7 & 43.1 \\
\hline
\end{tabular}

Source: SciVal

UoR maintains a significantly higher international collaboration than the other universities and has maintained a slowly increasing trend across the years. The other universities also have maintained a slow increase except for UoP where there appears a drop in 2016 and 2018 (Figure 8).

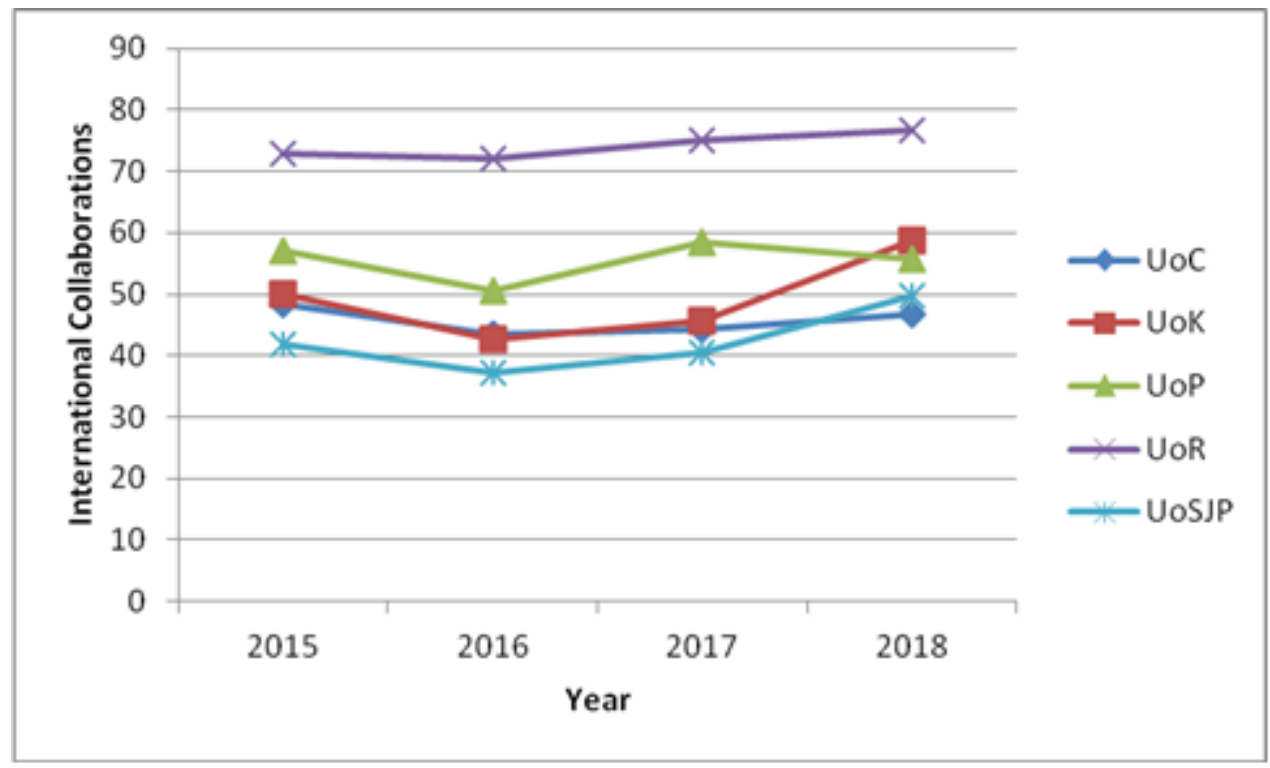

Figure 8. International Collaboration

UoP records the highest academic/corporate collaboration over the period at 2.2 and UoR records the lowest at 0.2 (Table 13). The trend of academic / corporate collaborations appears to be highly uneven (Figure 9). UoP has maintained an upward trend until 2017 then with a sharp drop in 2018. Regarding UoK, it depicts a sharp drop till 2017 and a slight upward trend in 2018. It also depicts a sharp annual drop in UoC and a rise across the period and UoSJP and UoR also show a downward trend towards 2018. 
Table 13. Academic/Corporate Collaboration

\begin{tabular}{llllll}
\hline University & $\mathbf{2 0 1 5}$ & $\mathbf{2 0 1 6}$ & $\mathbf{2 0 1 7}$ & $\mathbf{2 0 1 8}$ & Overall \\
\hline UoC & 1.8 & 0.6 & 2.3 & 0.5 & 1.3 \\
UoK & 2.9 & 1.7 & 0.8 & 1.2 & 1.6 \\
UoP & 2.5 & 2.5 & 2.8 & 1 & 2.2 \\
UoR & 0 & 0.6 & 0.5 & 0 & 0.3 \\
UoSJP & 1.3 & 1.7 & 1.6 & 0.6 & 1.2 \\
\hline
\end{tabular}

Source: SciVal

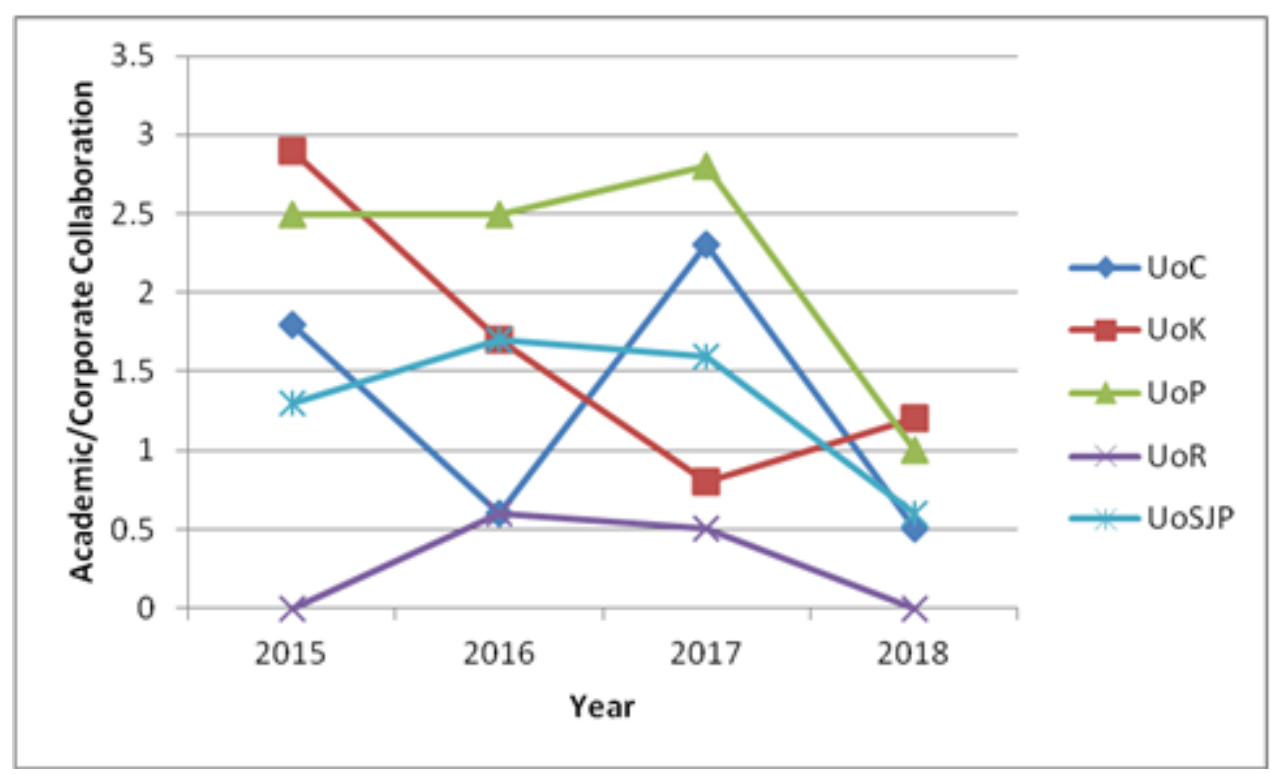

Figure 9. Academic / Corporate Collaboration

Research support services provided by the libraries

Of the 15 university libraries, librarians from twelve, responded and they have identified 33 services that could be categorized as; general services, training and publishing which they offer in support of research. All the libraries mentioned the nature of their collections including the special collections and databases; reported on conducive library environment, interlibrary loan and Document Delivery services. Two libraries mentioned that they provided a citation database and another, the online inquiry service. Training sessions are provided by almost all libraries with the majority offering training in literature searches, referencing styles and reference management software. Undergraduate orientations and information literacy training are provided by all. Under publishing, ten university libraries are 
represented in the university journal and editorial panels, and other services listed were provided only by a few libraries (Table 14).

Table 14. Research support service provided by the university libraries.

\begin{tabular}{|c|c|c|c|}
\hline General Services & Total & Publishing & Total \\
\hline $\begin{array}{l}\text { 1. General collection (books, } \\
\text { Periodicals, full text databases } \\
\text { and special collections) }\end{array}$ & 12 & $\begin{array}{l}\text { 20. Serving in university journal / } \\
\text { symposia editorial panels }\end{array}$ & 11 \\
\hline $\begin{array}{l}\text { 2. Providing a conducive library } \\
\text { environment }\end{array}$ & 12 & $\begin{array}{l}\text { 21. Serving in the Research } \\
\text { Council / Committee }\end{array}$ & 4 \\
\hline 3. Inter Library Loan Service & 12 & $\begin{array}{l}\text { 22. Recommending good quality / } \\
\text { predatory journals }\end{array}$ & 3 \\
\hline $\begin{array}{l}\text { 4. Document Delivery Service } \\
\text { through CONSAL / HELLIS / } \\
\text { BLDSS / Personal Contacts }\end{array}$ & 12 & $\begin{array}{l}\text { 23. Providing information on } \\
\text { Indexing services /Indexed } \\
\text { Journals }\end{array}$ & 3 \\
\hline $\begin{array}{l}\text { 5. Maintaining Institutional } \\
\text { Repository }\end{array}$ & 11 & $\begin{array}{l}\text { 24. Promoting Open Access } \\
\text { Journal information }\end{array}$ & 2 \\
\hline 6. Providing Citation databases & 2 & $\begin{array}{l}\text { 25. Developing a plagiarism policy } \\
\text { for the university }\end{array}$ & 2 \\
\hline 7. Online inquiry service & 2 & 26. Publishing university journals & 1 \\
\hline Training Sessions & & $\begin{array}{l}\text { 27. Providing DOI numbers for } \\
\text { university published articles }\end{array}$ & 1 \\
\hline 8. Referencing styles & 11 & $\begin{array}{l}\text { 28. Providing a list of proof } \\
\text { readers }\end{array}$ & 1 \\
\hline 9. Searching for literature & 8 & $\begin{array}{l}\text { 29. Supporting academics to } \\
\text { develop Google / ORCID/ RG } \\
\text { profiles }\end{array}$ & 1 \\
\hline $\begin{array}{l}\text { 10. Organize training by reputed } \\
\text { Publishers }\end{array}$ & 9 & $\begin{array}{l}\text { 30. Having a Research Support } \\
\text { Unit /website }\end{array}$ & 1 \\
\hline $\begin{array}{l}\text { 11. Plagiarism detection and } \\
\text { training to self-check }\end{array}$ & 6 & $\begin{array}{l}\text { 31. Posting permission granted } \\
\text { notices, as needed, for } \\
\text { copyrighted material }\end{array}$ & 1 \\
\hline $\begin{array}{l}\text { 12. Reference Management } \\
\text { Software }\end{array}$ & 6 & $\begin{array}{l}\text { 32. virtual help and enquiry service } \\
\text { trough library website }\end{array}$ & 1 \\
\hline 13. Research Skills & 3 & $\begin{array}{l}\text { 33. Providing Liaison Librarians } \\
\text { for each Faculty }\end{array}$ & 1 \\
\hline 14. How to do lit Reviews & 3 & & \\
\hline 15. Using citation databases & 3 & & \\
\hline $\begin{array}{l}\text { 16. One-to-one sessions for users / } \\
\text { Ask a librarian }\end{array}$ & 3 & & \\
\hline 17. Presentation Skills & 1 & & \\
\hline
\end{tabular}


18. Thesis / Dissertation Formats 1

19. Teaching LaTex software for 1 dissertation writing

20. Undergraduate training sessions

\section{Recommendations}

Present study evaluated the research productivity of five Sri Lankan State universities which are listed in the four international ranking systems using three criteria of SciVal; scholarly output, citation impact and collaboration. It further studied what services are offered by the Sri Lankan university libraries to support the research productivity.

Within the study period the number of publications in the Scopus database has increased significantly. Yet, despite having the highest number of publications, the growth of scholarly output of UoP has dropped to the least position, while UoSJP which has made the least contribution of scholarly publications during the period considered, shows the highest growth rate. UoC has maintained the highest number of authors as well as the highest growth rate, but UoP which had the second highest number of authors included in Scopus during the period considered, their growth rate has dropped to the fifth place out of the five universities. All other universities show a positive growth in the number of authors. Although UoP has the highest contribution of publications and UoC has the highest number of authors in Scopus, it is UoR that has the highest number of publications in top journal percentile portraying that they publish more high quality papers. UoR recorded the highest number of views followed by UoP.

UoP showed the highest number of citations, but UoR reported the highest h5-index, implying that the citations for UoR publications were higher during the past five years. As the Research Metrics Guidebook (Elsevier 2019c) mentions, a FWCI of 1.00 indicates that publications have been cited exactly based on the global average for similar publications. It further explains that the FWCI of the entire Scopus database is 1.00. Accordingly, UoP and UoR have claimed FWCI greater than 1.00 across the years. This indicates that their publications have been cited more than the expected rate based on the global average for similar publications. 
Of the universities studied, UoR has the highest number of collaborations, but UoP had the highest number of academic / corporate collaborations indicating that UoP has the best collaboration with the industry of the country.

The services offered by the university libraries indicated that they provide all basic services, yet only one or two universities have started providing services which directly support research. None of the libraries reported any support services identified in the literature review i.e. Research Data Management, Bibliometric support services to measure the research impact, Open access material related services and training in using related tools (i.e. SHERPA/ Romeo), or digital curation.

Based on the findings, several recommendations can be made for the universities to consider in improving their research productivity; the universities covered by the study must pay attention to maintain a continuous growth of their scholarly publications indexed in Scopus and increasing the number of authors contributing to scholarly publications; while maintaining a continuous growth in the publications, the universities must increase their contributions to the top journal percentile; universities must attempt to increase the citations count which will increase the $h 5$-index. To achieve a FWCI of 1.00 and to maintain its stability; all universities must concentrate on increasing collaborations in the national and international contexts and increase the collaboration with the corporate sector; university libraries need to develop a more focused systems to support scholarly publications and to guide research by providing consultancy and training in research. This recommendations cannot be implemented individually by the academics or the librarians but it is essential to have university level strategic plans incorporating both the academic departments and the library service with "improving research productivity" as a key initiative. The support of the University Grants Commission at the national level is vital to raise the research productivity of all universities under its purview to global standards.

Acknowledgement - The two-week trial access provided to the University of Colombo by Elsevier is greatly appreciated.

\section{References}

Abramo, G., D'Angelo, C.A. (2014). How do you define and measure research productivity? Scientometrics, 101(2), 1129-1144. DOI: 10.1007/s11192-014-1269-8 
Aponsu, G.M.R.D. (2017). Sri Lanka In: Productivity in Higher Education Research insights for universities and governments in Asia. Asian Productivity Organization. Tokyo. 216-247

Aslam, M. (2017). Current trends and issues affecting academic libraries and leadership skills. Library Management, 39(4), 78-92. https://doi.org/ 10.1108/LM-10-2016-0076

Ball, A., \& Duke, M. (2015). How to Track the Impact of Research Data with Metrics. DCC How-to Guides. Edinburgh: Digital Curation Centre. Retrieved from http://www.dcc.ac.uk/resources/how-guides. Accessed on $3^{\text {rd }}$ May 2019.

Bornmann L., \& Leydesdorff L. (2013). Macro-indicators of citation impacts of six prolific countries: Incites data and the statistical significance of trends. PLoS One, 8(2). https://doi.org/10.1371/journal.pone.0056768

Brown, S., Alvey, E., Danilova, E., Morgan, H., \& Thomas, A. (2018). Evolution of research support services at an academic library: specialist knowledge linked by core infrastructure. New Review of Academic Librarianship, 24(3-4), 337-348. https://doi.org/10.1080/13614533.2018. 1473259

Chandani, J.G., \& Wijayasundara, N.D. (2019). Visibility of University of Sri Jayewardenepura in Scopus. Retrieved from http://dr.lib.sjp.ac.lk/handle/123456789/8449

Corrall, S., Kennan, M.A., \& Afzal, W. (2013). Bibliometrics and research data management services: emerging trends in library support for research. Library Trends, 61(3), 636-674.

Delaney, G. \& Bates, J. (2015). Envisioning the academic library: a reflection on roles, relevancy and relationships. New Review of Academic Librarianship, 21(30), 30-51.

Elsevier (2019a). SciVal: Build your views on the world's research. Retrieved from https://www.elsevier.com/_data/assets/pdf_file /0011/927578/SciVal_Factsheet_WEB.pdf

Elsevier (2019b). SciVal. Retrieved from https://www.elsevier.com/ solutions/scival 
Elsevier (2019c). Research Metrics Guidebook. Retrieved from https://www.elsevier.com/_data/assets/pdf_file/0020/53327/ELSV13013-Elsevier-Research-Metrics-Book-r5-Web.pdf

Erfanmanesh, M., \& Nojavan, F. (2016). Qualitative and quantitative status and international visibility of Iranian journals indexed in Journal Citation Reports. Iranian Journal of Information Processing \& Management, 32 (1), 51-73.

Erfanmanesh, M., Tahira, M., \& Abrizah, A. (2017). The publication success of 102 nations in Scopus and the performance of their Scopus-indexed journals. Publishing Research Quarterly, doi: 10.1007/s12109-017-95405.

Fernando, R.L.S., Hemachandra, D.W.K., and Muthulingam, A. (2015). An assessment of the social science research environment of the Sri Lankan state university system. VJM, 4(2), 01-26.

Gadhoum, Y., \& Karam, Y. (2016). The determinants of research productivity in public versus private Saudi universities. Asia Pacific Journal of Advanced Business and Social Studies, 2(2), 625-660.

Günay, Asli and Haliloğlu, Ebru Yüksel (2018). A case study on measuring research efficiency of public universities in Turkey. Journal of University Research, 1(2), 36-42.

Gupta, B. (2012). Sri Lanka S\&T output during 2001- 2010: A scientometric assessment. Malaysian Journal of Library \& Information Science, 17(3), 49-65.

Haddow, G., \& Mamtora, J. (2017). Research support in Australian academic libraries: services, resources, and relationships. New Review of Academic Librarianship, 23(2-3), 89-109.

Keller, A. (2015). Research support in Australian university libraries: an outsider view. Australian Academic and Research Libraries, 46(2), 73 85.

Kennan, M.A., Corrall, S., \& Afzal, W. (2014). "Making space" in practice and education: research support services in academic libraries. Library Management, 35(8/9), 666-683. 
Khumbar, R. (2014). Academic library's responses to the emerging trends in higher education. DESIDOC Journal of Library and Information Technology, 34(6), 477-485.

King, D.A. (2004), The scientific impact of nations. Nature, 430, 311-331.

Mehbuba, D., \& Rousseau, R. (2010). Scientific research in the Indian subcontinent: selected trends and indicators 1973-2007 comparing Bangladesh, Pakistan and Sri Lanka with India, the local giant. Scientometrics, 84 (2), 403-420.

Mwaniki, P.W. (2018). Envisioning the future role of librarians' skills, services and information resources. Library Management, 39(1/2), 2-11.

Navaneethakrishnan, S. (2013). Sri Lankan research output at international level-A picture from Scopus. $2^{\text {nd }}$ International Conference on Social Sciences organized by Faculty of Social Sciences, University of Kelaniya, $22^{\text {nd }}-23^{\text {rd }}$ November 2013.

Navaneethakrishnan, S. (2014). Authorship patterns and degree of collaboration of Sri Lankan scientific publications in Social sciences and Humanities - a picture from SCOPUS. Library Philosophy and Practice, doi: http://digitalcommons.unl.edu/libphilprac/1153

Nejati, A., \& Jenab, S.M.H. (2010). A two-dimensional approach to evaluate the scientific production of countries (case study: the basic sciences). Scientometrics, 84 (2), 357-364.

Pethiyagoda, U. (2005). Research productivity in Sri Lanka. Journal of National Science Foundation Sri Lanka, 33(1), 1-2.

Pratheepan, T. (2011). Research productivity of Sri Lankan universities during 1999-2010 based on the ISI Web of Science database: a Scientometric study. Proceeding of the University Librarians Association Sri Lanka, 288 - 295.

Pratheepan, T. \& Weerasooriya, W.A. (2015). The publication output and impact of various faculties in Sri Lankan Universities: a scientometric assessment and policy implications. Journal of the University Librarians' Association of Sri Lanka, 19(1), 54-70. 
Ranking web of universities (2019). Retrieved from https://www.webometrics.info. Accessed on $3^{\text {rd }}$ May 2019.

Research Information Network and Research Libraries UK, (2011). The value of libraries for research and researchers. Retrieved from https://www.rluk.ac.uk/wp-content/uploads/2014/02/Value-of-Librariesreport.pdf

Senaratne, Ranjith (2015). Creating vibrant research culture and rich intellectual ambience in Sri Lankan universities. The Island. 10 March.

Sewell, C., \& Kingsley, D. (2017). Developing the $21^{\text {st }}$ century academic librarian: the research support ambassador programme. New Review of Academic Librarianship. 23(2-3), 148-158.

Shelley, M., \& Jackson, M. (2018). Research data management compliance: is there a bigger role for university libraries? Journal of the Australian Library and Information Association, 67(4), 394-410.

Si, L., Zeng, Y., Guo, S., \& Zhuang, X. (2019). Investigation and analysis of research support services in academic libraries. The Electronic Library, 37(2), 281-301.

Smith, M.J., Weinberger, C., Bruna, E.M., \& Allesina, S. (2014). The scientific impact of nations: Journal placement and citation performance. PLoS ONE, 9(10), e109195.

Tafreshi, G.H., Imani, M.N., \& Ghashlag, P.M. (2013). Designing a model for research productivity evaluation of faculty of district 2 of Islamic Azad University of Iran. World Applied Sciences Journal, 21 (12): 17081720 .

University Grants Commission (2018). Sri Lanka University Statistics 2017. Colombo: University Grants Commission.

Zhao, L. (2014). Riding the wave of open access: providing library research support for scholarly publishing literacy. Australian Academic and Research Libraries, 45(1), 3-18. 